\title{
KẾT QUẢ ĐIỀU TRỊ NGOẠI KHOA DÃN TĨNH MẠCH NÔNG CHI DƯớI MẠN TÍNH
}

Văn Minh Trí* Nguyê̂n Hoài Nam*

\section{TÓM TẮT}

Từ 08/2004-08/2006 có 157 bệnh nhân dãn tĩnh mạch chi dưới mạn tính được phẫu thuật tại BV Đại Học Y Dược. Nữ gặp nhiều hơn nam $(2,2 / 1)$ và có liên quan đến yếu tố nghề nghiệp. Chỉ định ngoại khoa được áp dụng cho những trường hợp dãn tĩnh mạch từ độ II trở lên. Phẫu thuật Stripping đơn thuần hoặc kèm theo Muller đạt thành công cao và mang tính thẩm mỹ. Phẫu thuật điều trị dãn tĩnh mạch nông chi dưới ít biến chứng, đạt kết quả tốt và mang lại sự hài lòng cho bệnh nhân. Chỉ định điều trị ngoại khoa cho những bệnh nhân bị dãn tĩnh mạch từ độ II trở lên.

\section{SUMMARY}

THE RESULTS OF SURGICAL TREATMENT OF

\section{CHRONIC VENOUS INSUFFICIENCY}

From 2004-August to 2006-August, at the Medical University Hospital, we performed operation for 157 the lower extremity varicose disease. More females were subtract to kind of disease than male $(2,2 / 1)$. Risk factors related to working condition. Surgical indications were for cases from class two above. Stripping only or with Muller resulted in great success and better cosmetic. Surgical treatment of the lower extremity varicose disease has lower complications, and the results are more satisfactory. Operation should be given to patient from class two.

\section{I. ĐẠTT VẦN ĐỀ:}

Bệnh lý dãn tĩnh mạch nông chi dưới có liên quan tới sự trào ngược và suy giảm hồi lưu trong lòng tĩnh mạch. Tuy bệnh không gây tử vong, nhưng theo thời gian gây ảnh hưởng đến công việc, sinh hoạt và chất lượng cuộc sống của bệnh nhân.

Bệnh gặp nhiều ở các nước phát triển, có liên quan mật thiết đến lối sống. Ở Mỹ, có trên 20 triệu người dân mắc bệnh này. Ở Nhật, $45 \%$ nữ công nhân bị suy tĩnh mạch chi dưới mạn tính.

Sự phát triển kinh tế đất nước trong thời gian đã qua mang lại đời sống kinh tế cao cho nhân dân, thì đồng thời bệnh dãn tĩnh mạch chi dưới mạn tính cũng phát triển theo và được người dân chú ý hơn. Nhu cầu điều trị bệnh ngày càng tăng, nhưng lựa chọn phương pháp điều trị nào vẫn còn chưa thống nhất trong các thầy thuốc nội và ngoại khoa. Vì vậy chúng tôi thực hiện nghiên cứu này nhằm đánh giá kết quả điều trị ngoại khoa bệnh dãn tĩnh mạch chi dưới mạn tính tại bệnh viện Đại học Y dược, qua đó rút ra chỉ định, phương pháp phẫu thuật và tìm hiểu các yếu tố nguy cơ của bệnh.

\section{II. ĐỐI TƯợG VÀ PHƯƠNG PHÁP NGHIÊN CÚU:}

Hồi cứu, mô tả 157 trường hợp bệnh nhân dãn tĩnh mạch chi dưới mạn tính được phẫu thuật tại đơn vị Phẫu thuật Lồng ngực mạch máu bệnh viện Đại Học Y Dược từ tháng 08/2004 đến tháng 08/2006.

\section{KẾT QUẢ NGHIÊN CÚU:}

Qua nghiên cứu 157 trường hợp dãn tĩnh mạch chi dưới mạn tính được phẫu thuật trong

* Bộ môn Ngoại lồng ngưc tim mạch - ĐH Y Dược TP. HCM Ngườ chịu trách nhiệm khoa học: PGS.TS Nguyễn Hoài Nam Ngày nhận bài: 01/02/2019 - Ngày Cho Phép Đăng: 23/03/2020 Phản Biện Khoa học: PGS.TS. Đặng Ngoc Hùng GS.TS. Lê Ngoc Thành 
thời gian từ tháng 8 năm 2004 đến tháng 8 năm 2006, tại đơn vị Phẫu thuật lồng ngực và mạch máu bệnh viện Đại Học Y Dược, các kết quả được ghi nhận như sau:

Giới: 108 nữ, 49 nam.

Tỷ lệ nữ/nam khoảng 2,2/1.
Tuổi: trung bình là 52,8.

nhỏ nhất: 23 , lớn nhất: 80 .

Có 54 bệnh nhân bị cả 2 chân, chiếm 34.4\%, 103( 65.6\% ) bệnh nhân chỉ bị 1 chân.

* Nghề nghiệp:

\begin{tabular}{lcc}
\hline \multicolumn{1}{c}{ Nghề nghiệp } & Số BN & Tỷ lệ \% \\
\hline Giáo viên & 33 & $21,1 \%$ \\
Buôn bán & 38 & $24,2 \%$ \\
Thợ may & 17 & $10,8 \%$ \\
Nông & 47 & $29,9 \%$ \\
Nhân viên hành chính & 14 & $8,9 \%$ \\
Khác & 8 & $5.1 \%$ \\
\hline
\end{tabular}

Đa số bệnh nhân có nghề nghiệp liên quan đến đứng, ngồi nhiều (86\%).

Thời gian từ lúc bệnh đến lúc phẫu thuật:

\begin{tabular}{lcc}
\hline & Thời gian & Số BN \\
\hline$<5$ năm & $38(24,2 \%)$ \\
$5-10$ năm & $43(27,4 \%)$ \\
$>10$ năm & $76(48,4 \%)$ \\
\hline
\end{tabular}

Đa số bệnh nhân có thời gian mắc bệnh kéo dài

Dấu hiệu lâm sàng:

\begin{tabular}{lcc}
\hline \multicolumn{1}{r}{ Triệu chứng } & Số ca & Tỷ lệ \% \\
\hline Dãn tĩnh mạch nông & 157 & $100 \%$ \\
Nặng chân, phù & 123 & $65,6 \%$ \\
Vọp bẻ & 44 & $28 \%$ \\
Sạm da & 31 & $19,8 \%$ \\
Tê bì & 27 & $17,2 \%$ \\
Loét tĩnh mạch & 20 & $12,7 \%$ \\
\hline
\end{tabular}

Xếp loại lâm sàng theo CEAP

\begin{tabular}{ccc}
\hline CEAP & Số bệnh nhân & Tỷ lệ \% \\
\hline 2 & 25 & $15,9 \%$ \\
3 & 81 & $51,6 \%$ \\
4 & 31 & $19,8 \%$ \\
5 & 20 & $12,7 \%$ \\
\hline
\end{tabular}


Chúng tôi chỉ xếp loại theo lâm sàng $(\mathrm{C})$, chưa tính đến bệnh nguyên, giải phẫu và sinh bệnh học. Chúng tôi xếp loại theo độ cao nhất, ghi nhận độ 2 và 3 chiếm đa số $(67,5 \%)$

Dấu hiệu cận lâm sàng:

\begin{tabular}{lc}
\hline Siêu âm Doppler & Số bệnh nhân \\
\hline Dãn tĩnh mạch nông & $157(100 \%)$ \\
Suy van tĩnh mạch sâu & $128(81,5 \%)$ \\
\hline
\end{tabular}

Phương pháp phẫu thuật:

\begin{tabular}{lc}
\hline Phương pháp phẫu thuật & Số lần \\
\hline Muller & 4 \\
Stripping & 66 \\
Stripping + Muller & 141 \\
\hline
\end{tabular}

Chúng tôi thực hiện phẫu thuật Stripping lấy bỏ tĩnh mạch hiển lớn qua đường rạch da ở vùng bẹn và mắt cá trong kết hợp với $\mathrm{PT}$ Muller lấy bỏ các TM dãn tại chỗ. Có $4 \mathrm{BN}$ chỉ áp dụng PT Muller do vị trí $\mathrm{TM}$ dãn nàm trên đường đi $\mathrm{TM}$ hiển bé.

\section{Biến chứng và kết quả:}

\begin{tabular}{lcc}
\hline \multicolumn{1}{c}{ Kết quả-biến chứng } & Số ca & Tỷ lệ \% \\
\hline Cải thiện triệu chứng nặng chân & 119 & $75,8 \%$ \\
Đau và bầm dọc đường rút tĩnh mạch & 31 & $19,7 \%$ \\
Tổn thương thần kinh hiền & 11 & $7 \%$ \\
Tụ máu vết mổ ở bẹn & 1 & \\
Huyết khối tĩnh mạch sâu & 0 & \\
Tử vong & 0 & \\
\hline
\end{tabular}

\section{BÀN LUẬN:}

\subsection{Nguyên nhân và yếu tố thuận lọii:}

Tác giả G.Fowkes, Giáo sư chuyên ngành dịch tễ học (Anh quốc) 2001: bệnh lý tĩnh mạch chi dưới là bệnh thường gặp gần khoảng $1 / 3$ dân số phương Tây.Tần suất mắc bệnh gia tăng theo tuổi, có thể có liên quan đến yếu tố cơ địa. Việc đứng lâu là một yếu tố nguy cơ.

Ngoài ra còn có tình trạng béo phì, những lần có thai trước đây thường kết hợp với sự hiện diện của dãn tĩnh mạch nhưng bằng chứng về mối liên quan này không hằng định.

Jari O Laurikka, Phần Lan, trong một nghiên cứu về dịch tễ cho thấy tỷ lệ nam/ nữ là $1 / 3$, yếu tố thuận lợi để bệnh phát triển là phái nữ, số lần có thai, tính di truyền gia đình, tuổi càng lớn càng dễ mắc bệnh, và cuối cùng là hoạt động nghề nghiệp phải đứng lâu. Việc đứng lâu làm bơm cơ kém hoạt động nên không ép máu tĩnh mạch về đưa đến sự ứ đọng máu tĩnh mạch [2]. 
Trong nghiên cứu của chúng tôi, bệnh gặp ở nữ nhiều hơn nam (tỷ lệ nữ/nam là $2,2 / 1$ ) và hầu hết bệnh nhân có nghề nghiệp đòi hỏi phải đứng lâu $(86 \%)$.

\subsection{Phân loại lâm sàng:}

Năm 1994, một nhóm các chuyên gia Quốc tế đưa ra bảng phân loại CEAP về bệnh lý tĩnh mạch chi dưới và nhanh chóng được chấp nhận trên toàn thế giới. Phân loại CEAP được xem là phân loại lý tưởng nhất vì nó xem xét đến tất cả những khía cạnh chính của bệnh lý tĩnh mạch chi dưới như lâm sàng, bệnh nguyên, giải phẫu học và sinh lý bệnh v.v...[5]

Trong nhóm nghiên cứu của chúng tôi, bệnh nhân cũng được xếp loại theo CEAP. Tuy nhiên không đánh giá đầy đủ tất cả các mặt, chỉ xếp loại theo lâm sàng, trong đó độ 2 và 3 gặp nhiều nhất chiếm đến $67,5 \%$.

Siêu âm Doppler là phương tiện chẩn đoán đơn giản hiệu quả và an toàn trong việc khảo sát bệnh lý tĩnh mạch. Chụp tĩnh mạch cản quang có hiệu quả hơn siêu âm Doppler trong việc phân biệt nguyên nhân nguyên phát và thứ phát tuy nhiên khó thực hiện và có thể có tai biến thậm chí đưa đến tử vong do choáng với thuốc[5].

Trong nghiên cứu này, chúng tôi chỉ sử dụng siêu âm Doppler để khảo sát hệ tĩnh mạch, và tất cả đều phát hiện được bệnh lý.

\subsection{Về chỉ định và phương pháp phẫu thuật:}

Mục đích của phẫu thuật là phải đảm bảo lấy hết những tĩnh mạch dãn và nguồn gây ra tăng áp lực tĩnh mạch, đạt tính thẩm mỹ cao nhất khi có thể và làm giảm tối đa các biến chứng[3].

J. Ciucci 1999[1], trong công trình nghiên cứu về bệnh lý tĩnh mạch chi dưới cho thấy: ông chỉ định mổ cho những bệnh nhân bị dãn tĩnh mạch chi dưới mạn tính từ độ $3 \mathrm{CEAP}$ trở lên và phương pháp là $100 \%$ cột quai tĩnh mạch hiển đùi, $88 \%$ lột bỏ tĩnh mạch hiển trong kèm hoặc không với lột bỏ tĩnh mạch hiển ngoài và $2,9 \%$ phẫu thuật Muller.

Theo Khirurgiia 2002 [4], để điều trị bệnh lý tĩnh mạch chi dưới, phẫu thuật cột quai tĩnh mạch hiển - đùi, rút bỏ tĩnh mạch hiển trong và lấy các nhánh từng đoạn (phẫu thuật Muller) là phẫu thuật đơn giản, ít biến chứng và thẩm mỹ.

Chúng tôi chỉ định điều trị bằng phương pháp ngoại khoa cho những bệnh nhân dãn tĩnh mạch chi dưới mạn tính từ độ 2 trở lên. Tức là khi đã có tĩnh mạch dãn trên lâm sàng. Phương pháp phẫu thuật là rút bỏ tĩnh mạch hiển lớn (phẫu thuật Stripping) với đường mổ nhỏ ở vùng bẹn và mắt cá trong. Những tĩnh mạch dãn tại chỗ được lấy bỏ qua những đường rạch da ngắn tại chỗ (phẫu thuật Muller).

Với phương pháp mổ này hầu như tất cả các tĩnh mạch dãn đều được lấy bỏ, đồng thời với những đường rạch da ngắn đạt được hiệu quả thẩm mỹ cao. Sau mổ toàn bộ chân của bệnh nhân được băng ép bằng băng thun để cầm máu.

\subsection{Kết quả sớm điều trị ngoại khoa:}

Cũng theo J.Ciucci[1], biến chứng sau mổ ghi nhận: về tổn thương thần kinh là $0 \%$, tụ máu dọc lộ trình rút tĩnh mạch là $13 \%$, nhiễm trùng là $1,7 \%$. Trong nhóm nghiên cứu của chúng tôi: tổn thương thần kinh gặp trong 7\% và bầm dọc đường rút tĩnh mạch là 19,7\%, còn đạt kết quả tốt $>70 \%$.

Do những bệnh nhân của chúng tôi có thời gian bệnh kéo dài, tĩnh mạch dãn rất nhiều nên chúng tôi phải làm Muller nhiều hơn, có lẽ vì vậy mà tỷ lệ đau - bầm dọc đường đi tĩnh mạch cao hơn.

\section{KẾT LUẬN:}

Qua nghiên cứu 157 trường hợp bệnh nhân bị dãn tĩnh mạch chi dưới mạn tính được phẫu 
thuật tại đơn vị Phẫu thuật lồng ngực và mạch máu bệnh viện Đại học $\mathrm{Y}$ dược, trong thời gian từ tháng 08/2004 đến tháng 08/2006. Chúng tôi rút ra các kết luận sau:

- Bệnh xảy ra ở nữ nhiều hơn nam và có liên quan đến hoạt động nghề nghiệp phải đứng lâu.

- Chỉ định điều trị khi có tĩnh mạch dãn trên lâm sàng (từ độ 2),

- Phẫu thuật Stripping kết hợp với phẫu thuật Muller khi cần mang lại kết quả cao, it biến chứng.

\section{TÀI LIẸU THAM KHẢO}

1.Ciucci J. (1999). Quality control in varicose vein surgery: significance and
2. Jari. O. Laurikka. Risk indications for varicose veins in forty to sixty Y.O in the tempere varicose vein study. World Journal of Surgery. June 2002, V. 26, N. 6. p 648.

3. John j. Bergan. Varicose veins: treatment by surgery and sclerotherapy. Vascular Surgery, vol. 2, 2000, p. 2007-2021.

4.Khirurgiia (Mosk). Surgical Technologies in the treatment of lower extremity varicose disease. (1): 10-5 Related Articles, Book, 2002.

5. Robert L. Kistner, Elna M. Masuda. A practical approach to the diagnosis and classification of chronic venous disease. Vascular Surgery, vol. 2, 2000, p. 1990-1999. 